\title{
Sudden Respiratory Symptoms as Presentation of a Liver Mass
}

\author{
Ana Luísa Santos ${ }^{\mathrm{a}-\mathrm{c}}$ Susana Lopes ${ }^{\mathrm{a}-\mathrm{c}}$ João Pacheco ${ }^{\mathrm{d}}$ Guilherme Macedo ${ }^{\mathrm{a}-\mathrm{c}}$ \\ a Department of Gastroenterology and Centro Hospitalar Universitário de São João, Porto, Portugal; \\ ${ }^{b}$ WGO Porto Training Center, Porto, Portugal; ${ }^{~}$ Porto Medical School and University of Porto, Porto, Portugal; \\ ${ }^{d}$ Pathology Department and Centro Hospitalar Universitário de São João, Porto, Portugal
}

\section{Keywords}

Dysphagia $\cdot$ Endobronchial invasion $\cdot$ Hepatocellular carcinoma $\cdot$ Endoscopic ultrasound

\section{Disfunção Respiratória Súbita Secundária a Nódulo Hepático}

\section{Palavras Chave}

Disfagia $\cdot$ Invasão endobrônquica $\cdot$ Carcinoma hepatocelular · Ecoendoscopia

\section{Clinical Case}

A 55-year-old man, with a past history of alcohol abuse, was admitted to hospital with hemoptysis, hoarseness, dysphagia for solids and anorexia with weight loss, with progressive worsening in the last 2 months. Thoracic computed tomography $(\mathrm{CT})$ scan showed a $9 \times 6 \times$ $8-\mathrm{cm}$ homogeneous mass with well-defined borders in the upper mediastinum with extension to the subcarinal region that caused apparent obliteration of the esophageal lumen (Fig. 1). A nodular liver lesion was found in

karger@karger.com www.karger.com/pjg

Karger"
(C) 2021 Sociedade Portuguesa de Gastrenterologia. Published by S. Karger AG, Basel

This is an Open Access article licensed under the Creative Common Attribution-NonCommercial-4.0 International License (CC BY-NC) (http://www.karger.com/Services/OpenAccessLicense), applicable to the online version of the article only. Usage and distribution for commercial purposes requires written permission. abdominal plans of CT, better characterized by magnetic resonance image (MRI), showing multiple ill-defined nodular lesions in the liver, with hypervascularity and wash-out, leading to the hypothesis of multifocal hepatocellular carcinoma or metastatic lesions of an unknown primary. An upper endoscopy was performed, confirming esophageal extrinsic compression, with normal mucosa. In rigid bronchoscopy, a bilateral endobronchial mass was seen, highly friable, causing reduction of the lumen of the left main bronchus in $70 \%$ due to extrinsic compression and mucosal infiltration. Histologically, this lesion was described as compatible with a non-small cell carcinoma, with the expression of citokeratine-7, without a clear definition of its lung origin. Mediastinal radiotherapy was performed to control symptoms, namely hemorrhage. In order to obtain a definite diagnosis of the mediastinal mass, endoscopic ultrasonography (EUS) was performed, showing a hypoechoic and homogeneous mass (Fig. 2), with hypervascular pattern and with a predominantly blue elastographic pattern, suggestive of malignancy (Fig. 3). An EUS-guided fine-needle biopsy was performed (Acquire, 25G, Boston Scientific ${ }^{\circledR}$ ); histology showed clusters of malignant cells (Fig. 4), with expression of Hep-par 1, findings that are compatible with metastasis of hepatocellular carcinoma (Fig. 5). 


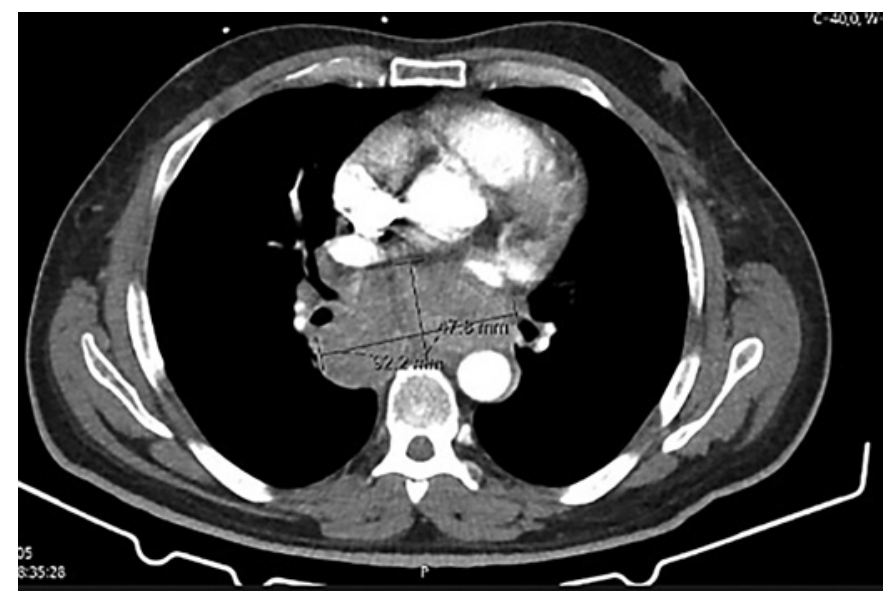

Fig. 1. Thoracic CT scan showing a mediastinal mass with apparent obliteration of the esophageal lumen.

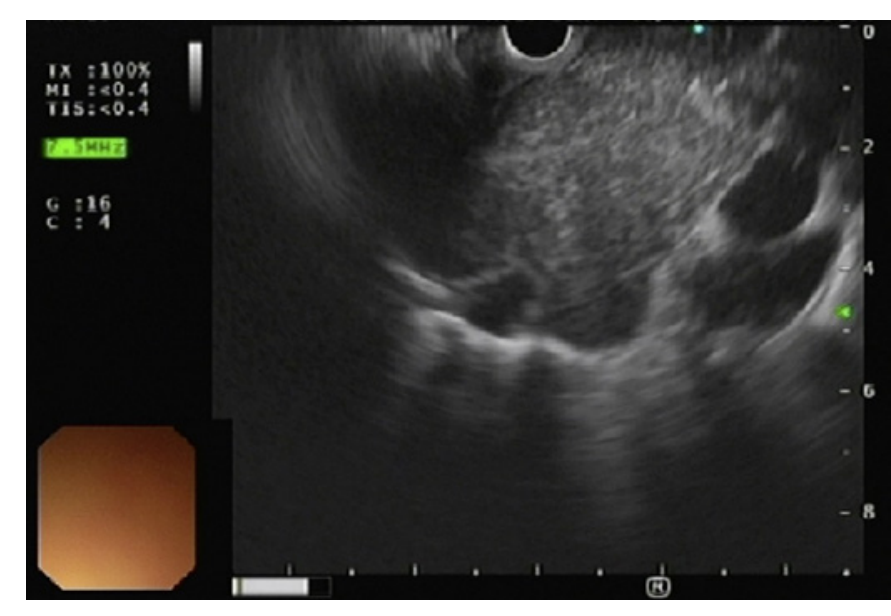

Fig. 2. EUS image showing an hypoechoic and homogeneous mass.
Fig. 3. EUS image showing a predominantly blue elastographic pattern, suggestive of malignancy.

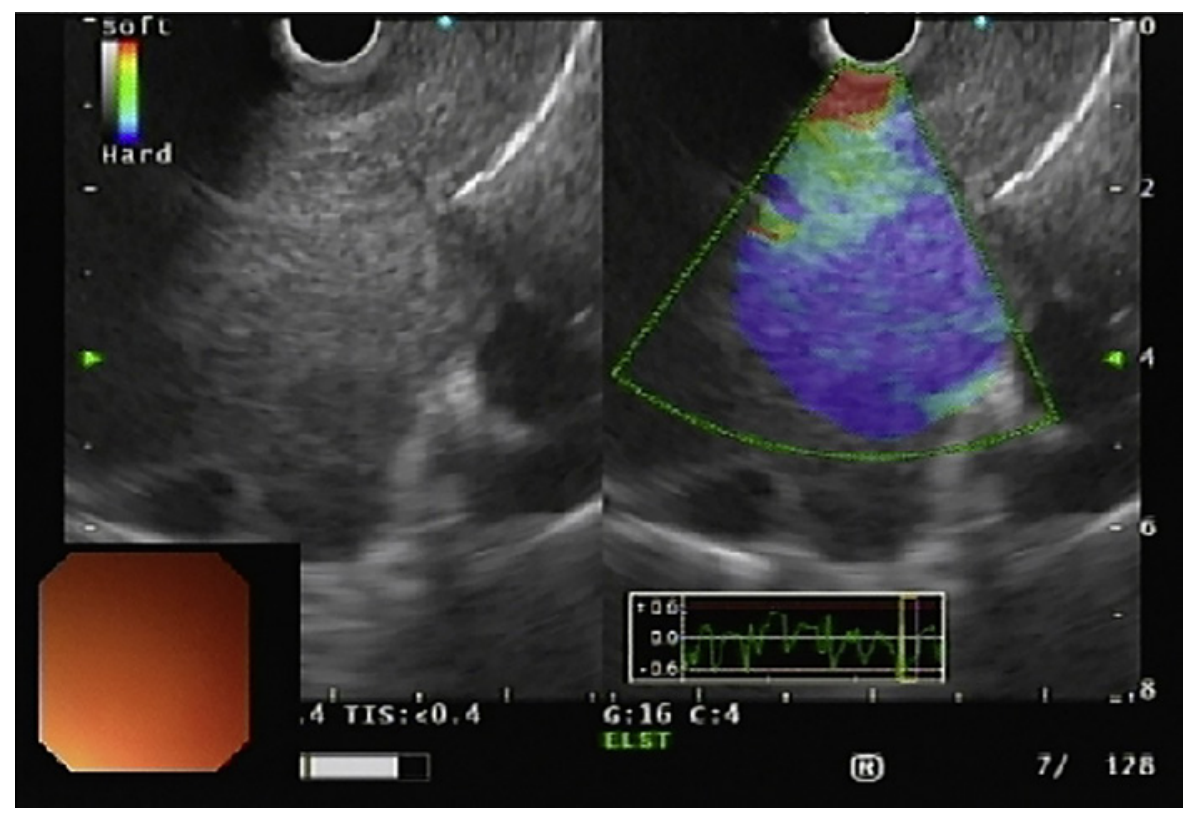

In view of these findings and in order to stage a potential underlying chronic liver disease, an ultrasound-guided liver biopsy was performed, confirming a liver cirrhosis. Despite the patient had a compensated liver cirrhosis (Child-Pugh A, 6 points), there was a progressive deterioration of functional status that made any type of systemic chemotherapy not viable.

The incidence of endobronchial metastasis from nonpulmonary malignancies ranges from 2 to $50 \%$ and usually the breast, kidney, colorectal, uterine cervix, sarcoma and skin origin predominate [1]. When related to hepa- tocellular carcinoma it is very rare, with an incidence of $0.04 \%$ in an advanced stage of the disease, and only 10 cases have been reported in the literature [2].

The definition of endobronchial metastases remains heterogeneous. Kiryu et al. [4] described a classification in 4 types, which was later modified by Akoglu et al. [3]: type I, direct metastasis to the bronchus, type II, bronchial invasion by parenchymal lesions; type III, bronchial invasion by a mediastinal or lymph node metastasis; and type IV, endobronchial invasion with lymphangitis carcinomatosis [3]. Our case represents a type III as we ob- 


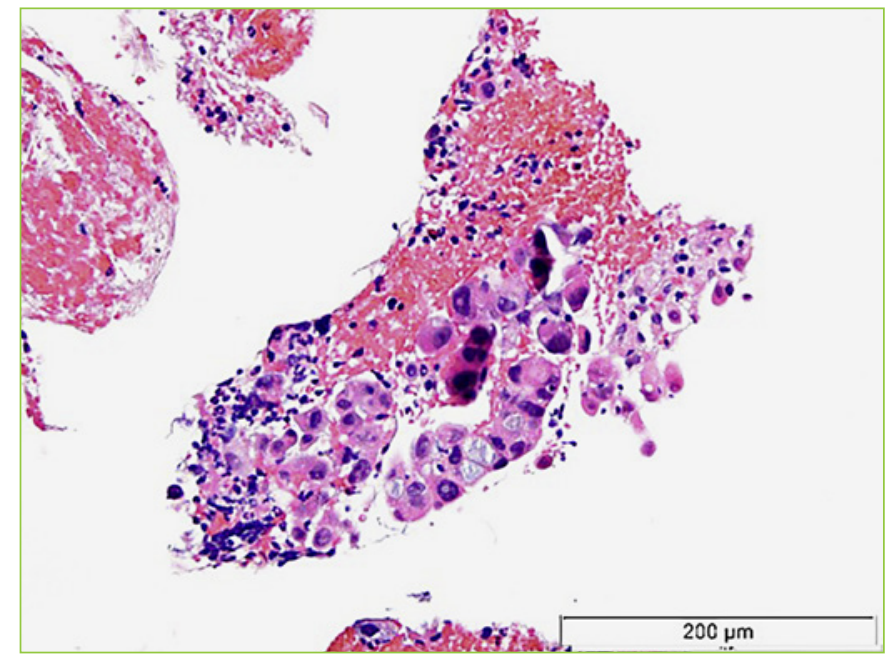

Fig. 4. Hematoxylin and eosin stain $(20 \times)$ with clusters of malignant cells.

served an endobronchial invasion by a mediastinal mass representing an HCC metastasis.

Despite endobronchial metastases being a rare presentation of HCC and associated with a poor prognosis, its prompt diagnosis is fundamental, in order to choose the adequate therapy and promote symptomatic relief. In our case, external radiotherapy photon beam was successfully used to re-establish patient airway and hemoptysis resolution.

Nowadays, less invasive techniques than mediastinoscopy, like EUS-guided sample, are recommended to confirm the etiologic diagnosis of mediastinal masses. In this case, EUS had an important role, together with endobronchial biopsies, in determining the origin of the primary tumor. Moreover, the type of needle chosen in this case was due to the hypervascularity of the lesion, in order to minimize potential hemorrhagic complications.

We reported this case due to the rarity of this pattern of HCC presentation as well as to demonstrate the crucial role of EUS in determining the etiology of a mediastinal mass.

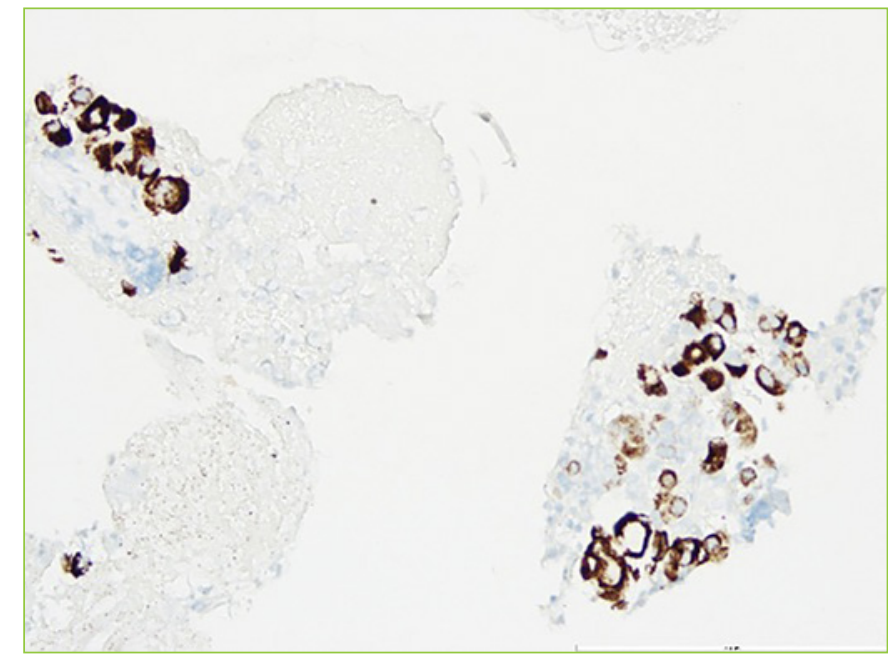

Fig. 5. Immunohistochemical expression of Hep-Par 1, compatible with metastasis of hepatocellular carcinoma.

\section{Statement of Ethics}

Informed consent was obtained from the patient for publication.

\section{Conflict of Interest Statement}

All authors have no personal conflicts of interest or financial relationships relevant to this publication to disclose.

\section{Funding Sources}

No funding was received.

\section{Author Contributions}

A.L.S. drafting of the manuscript; participating in the endoscopic procedure. S.L. responsible for the endoscopic procedure and critical revision of the manuscript. J.P. responsible for histological analysis. G.M. critical revision of the procedure.

\section{References}

Sudden Respiratory Symptoms as Presentation of a Liver Mass
1 Zhang Z, Mao Y, Chen H, Dong J, Yang L, Zhang L, et al. Endotracheal and endobronchial metastases in a patient with stage I lung adenocarcinoma. Ann Thorac Surg. 2014 May;97(5):e135-7.

2 Cheung FP, Russell PA, Alam NZ, Wright GM. Endobronchial metastases from hepatocellular carcinoma: a case report. Asian Cardiovasc Thorac Ann. 2019 Oct;27(8):703-6.
3 Akoglu S, Uçan ES, Çelik G, Şener G, Sevinç $\mathrm{C}$, Kilinç O, et al. Endobronchial metastases from extrathoracic malignancies. Clin Exp Metastasis. 2005;22(7):587-91.

4 Kiryu T, Hoshi H, Matsui E, Iwata H, Kokubo M, Shimokawa K, et al. Endotracheal/ endobronchial metastases: clinicopathologic study with special reference to developmental modes. Chest. 2001 Mar;119(3):768-75. 